Hamachi et al.

\title{
Glycols modulate terminator stem stability and ligand-dependency of a glycine riboswitch
}

\author{
Kokoro Hamachi $^{\mathrm{a}}$, Hikari Hayashi ${ }^{\mathrm{a}, 1}$, Miyuki Shimamura ${ }^{\mathrm{a}}$, Yuiha Yamaji ${ }^{\mathrm{a}}$, Ai Kaneko ${ }^{\mathrm{a}}$, \\ Aruma Fujisawa ${ }^{a}$, Takuya Umehara ${ }^{a}$ and Koji Tamura, ${ }^{a, b}$,* \\ ${ }^{\mathrm{a}}$ Department of Biological Science and Technology, Tokyo University of Science, 6-3-1 \\ Niijuku, Katsushika-ku, Tokyo 125-8585, Japan \\ ${ }^{\mathrm{b}}$ Research Institute for Science and Technology, Tokyo University of Science, 2641 \\ Yamazaki, Noda, Chiba 278-8510, Japan
}

*Corresponding author. Tel.: +81-3-5876-1472; fax: +81-3-5876-1614.

E-mail address: koji@rs.tus.ac.jp (K. Tamura)

${ }^{1}$ Present address: Department of Medical Genome Science, Graduate School of Frontier Sciences, The University of Tokyo, 5-1-5 Kashiwanoha, Chiba 277-8562, Japan.

Page 1 of 25

(C) 2013. This manuscript version is made available under the Elsevier user license http://www.elsevier.com/open-access/userlicense/1.0/ 
Hamachi et al.

\section{ABSTRACT}

The Bacillus subtilis glycine riboswitch comprises tandem glycine-binding aptamers and a putative terminator stem followed by the $g c v T$ operon. Gene expression is regulated via the sensing of glycine. However, we found that the riboswitch behaves in a "glycineindependent" manner in the presence of polyethylene glycol (PEG) and ethylene glycol. The effect is related to the formation of a terminator stem within the expression platform under such conditions. The results revealed that increasing PEG stabilized the structure of the terminator stem. By contrast, the addition of ethylene glycol destabilized the terminator stem. PEG and ethylene glycol have opposite effects on transcription as well as on stable terminator stem formation. The glycine-independency of the riboswitch and the effects of such glycols might shed light on the evolution of riboswitches.

Key words:

glycine riboswitch

terminator stem

stability

PEG

ethylene glycol 
Hamachi et al.

\section{Introduction}

Riboswitches are composed of a cis-acting RNA-based genetic control apparatus, which is located within the untranslated regions of the mRNA (Nudler and Mironov, 2004; Roth and Breaker, 2009; Winkler and Breaker, 2005). The binding of small ligands brings about structural changes within the riboswitches; this affects transcriptional or translational efficiency and therefore gene expression (Mandal et al., 2004; Yarnell and Roberts, 1999). The existence of riboswitches instead of protein regulators is important when considering evolutionary pathways, especially the transition from an RNA- to a protein-centric regulatory model. The glycine riboswitch (Mandal et al., 2004) is a naturally occurring RNA aptamer that recognizes the smallest and the most prebiotically abundant amino acid, glycine (Miller, 1953), suggesting that it might have been a remnant of early evolution of the ribonucleoprotein (RNP) world.

Two similar structural regions (I and II) are typically arranged in tandem and connected by a short nucleotide linker in the glycine riboswitch (Mandal et al., 2004). These two regions function as two glycine-binding aptamers, followed by a single expression platform. The results of bioinformatics searches suggest that the glycine riboswitches are localized upstream of the $g c v T$ operon, which controls the expression of enzymes involved in the metabolism of glycine (Mandal et al., 2004). In addition, the glycine riboswitch is known to work cooperatively: the binding of glycine to one of the two aptamers assists the subsequent binding of glycine to the second aptamer (Erion and Strobel, 2011; Kwon and Strobel, 2008; Mandal et al., 2004). The results of a small-angle X-ray scattering (SAXS) and hydroxyl radical footprinting study showed that glycine binding affects the arrangement of the tandem riboswitch (Lipfert et al., 2007). A crystal 
Hamachi et al.

structure of the tandem glycine riboswitch from Fusobacterium nucleatum revealed the glycine binding sites (Butler et al., 2011; Huang et al., 2010). On the other hand, in the 5'-elongated glycine riboswitches of Vibrio cholerae, the 5'-leader-linker interaction forms a kink-turn motif that abolishes glycine-binding cooperativity in glycine binding (Baird and Ferré-D’Amaré, 2013; Sherman et al., 2012). However, the molecular basis of the ON/OFF regulatory mechanism of glycine riboswitches is still unclear.

To date, more than 20 distinct classes of riboswitches have been identified (Erion and Strobel, 2011). The ability of riboswitches to regulate the efficiency of gene expression is determined by the ligand with which they interact. In the present study, we focused on the behavior of the putative intrinsic terminator stem present in the glycine riboswitch of Bacillus subtilis (Mandal et al., 2004). The last 11 nucleotides of aptamer II of the B. subtilis glycine riboswitch contains sequences that are complementary to a part of the expression platform, and the binding of glycine is expected to unfold the terminator stem, thereby accelerating the transcription by RNA polymerase. In the present study, we analyzed the formation of the terminator stem under various conditions and discussed the effect on RNA stability and its relationship with evolution of riboswitches. 
Hamachi et al.

\section{Materials and methods}

\subsection{Plasmid construction and preparation of oligonucleotides}

Unlabeled deoxyribonucleotides were synthesized by Operon Biotechnologies Inc. (Tokyo, Japan). HPLC-purified unlabeled or dye-labeled oligonucleotides with fluorescein and DABCYL (where fluorescein is a fluorophore, and DABCYL, a quencher) were prepared by Japan Bio Services Co. LTD. (Saitama, Japan). The concentrations of the oligonucleotide solutions were determined from the absorbance at a wavelength of $260 \mathrm{~nm}$. A PCR-amplified glycine riboswitch region from B. subtilis genomic DNA (a kind gift from Professor Koichi Ito, University of Tokyo) was ligated into the XbaI-site of the eGFP vector (pET23a, a kind gift from Professor Shigetoshi Miura, Tokyo University of Science) (Fig. 1). The plasmids of the deletion and substitution mutants were prepared using the PrimeSTAR Mutagenesis Basal Kit according to the manufacturer's protocol (TaKaRa). All the plasmid DNA sequences were confirmed by Operon Biotechnologies Inc. (Tokyo, Japan). PCR-amplified related regions of these plasmids were used as templates for the RNA transcription assays.

\subsection{In vitro transcription}

RNA preparation using T7 RNA polymerase was performed in a reaction mixture containing $40 \mathrm{mM}$ Tris- $\mathrm{HCl}(\mathrm{pH} 7.5), 10 \mathrm{mM}$ dithiothreitol, $2 \mathrm{mM}$ spermidine, $6 \mathrm{mM}$ magnesium chloride, $9 \mathrm{mM}$ each NTP, $\sim 0.2 \mathrm{mg} / \mathrm{ml}$ template DNA, and $5 \mathrm{mg} / \mathrm{ml}$ T7 RNA polymerase. The transcripts were purified via $8 \%$ polyacrylamide gel electrophoresis. For the preparation of T7 RNA polymerase, pT7-911Q plasmid (a kind gift from Dr. Subray S. Hegde, Albert Einstein College of Medicine) was transformed into E. coli BL21- 
Hamachi et al.

Codon Plus (DE3)-RIL strain (Stratagene). The enzyme was expressed and purified by using Ni-NTA agarose (Qiagen).

For the transcription assay, RNA transcription was performed in a reaction mixture containing $40 \mathrm{mM}$ Tris- $\mathrm{HCl}$ ( $\mathrm{pH} 8.0$ ), $10 \mathrm{mM}$ dithiothreitol, $8 \mathrm{mM}$ spermidine, $20 \mathrm{mM}$ magnesium chloride, $25 \mathrm{mM}$ sodium chloride, $9 \mathrm{mM}$ each NTP (pH 4.5 (Fig. 2, 3) or $\mathrm{pH} 8.0$ (Fig. 4)), $0.04 \mathrm{mg} / \mathrm{ml}$ template DNA, and $1.1 \mathrm{mg} / \mathrm{ml} \mathrm{T} 7 \mathrm{RNA}$ polymerase with various concentrations (shown in the figures) of glycine, polyethylene glycol (PEG) 4000 (average molecular weight: 3000), and ethylene glycol. The transcribed RNA was separated using ethidium bromide-containing $2 \%$ agarose gel electrophoresis and visualized.

\subsection{Electrophoretic mobility shift assay (EMSA)}

Briefly, $40 \mu \mathrm{M}$ of each RNA corresponding to the terminator stem (wild-type or bulgeless) in water was heated at $95^{\circ} \mathrm{C}$ for $5 \mathrm{~min}$ and chilled on ice for $5 \mathrm{~min}$. Then, an equal volume of Buffer A (80 mM Tris- $\mathrm{HCl}$ (pH 8.0), $40 \mathrm{mM}$ magnesium chloride, 50 $\mathrm{mM}$ sodium chloride) was added and the solutions were incubated at $37^{\circ} \mathrm{C}$ for $30 \mathrm{~min}$. After the addition of loading buffer containing glycerol, the solution was analyzed by electrophoresis through nondenaturing $10 \%$ polyacrylamide gels in TBE buffer ( $89 \mathrm{mM}$ Tris, $89 \mathrm{mM}$ borate, $2 \mathrm{mM}$ EDTA) (Takahashi et al., 2000). Two RNAs (Strand-1 and Strand-2) which have partially complementary sequences were also used as a dimer control. The specific sequences were as follows and the complementary parts are single and double underlined; wild-type terminator stem: 5'-

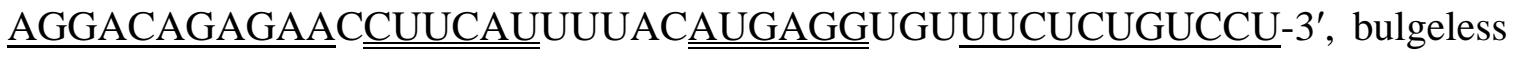


Hamachi et al.

terminator stem: 5'-AGGACAGAGAACUUCAUUUUACAUGAGGUUCUCUGUCCU3', Strand-1: 5'-AGGACAGAGAACUUCAUUUUACCUUCAUAGGACAGAGAA-3', Strand-2: $\quad$ 5'-UUCUCUGUCCUAUGAGGUUUACAUGAGGUUCUCUGUCCU-3'. tRNA $^{\text {Ala }}$ transcript and minihelix ${ }^{\text {Ala }}$ were also used as controls (Francklyn and Schimmel, 1989). The nucleotides were separated via $10 \%$ native PAGE. The gel was stained with $0.04 \%$ toluidine blue.

\subsection{Fluorescence resonance energy transfer (FRET) analysis}

The fluorophore, fluorescein, and the quencher DABCYL were attached to the 5'and 3'-termini of the terminator stem RNA and its derivatives, respectively. The RNAs were dissolved in water with various concentrations of PEG4000 and ethylene glycol. FRET measurements (Mergny, 1999; Mergny and Maurizot, 2001; Umehara et al., 2012) were carried out using an FP-6200 spectrofluorometer (JASCO Corporation, Tokyo, Japan) at room temperature using a $3 \times 3-\mathrm{mm}$ quartz cuvette, promptly after the preincubation at $95^{\circ} \mathrm{C}$ for $10 \mathrm{~min}$. For the emission spectra, the excitation wavelength was set at $490 \mathrm{~nm}$.

\subsection{UV-monitored thermal denaturation analysis}

UV-monitored thermal denaturation analysis was carried out using a DU-800 spectrophotometer (Beckman Inc.). The cell path length was $1 \mathrm{~cm}$. The UV-melting profiles of each RNA $(\sim 1 \mu \mathrm{M})$ were measured in Buffer B $(2.5 \mathrm{mM}$ sodium phosphate (pH 7.0), $25 \mathrm{mM}$ sodium chloride, $12.5 \mu \mathrm{M}$ EDTA (pH 8.0), and PEG or ethylene glycol with the concentrations listed in the figures) at a scan rate of $1.0^{\circ} \mathrm{C} / \mathrm{min}$ in the range of 
Hamachi et al.

$15-40^{\circ} \mathrm{C}$, and at $0.5^{\circ} \mathrm{C} / \mathrm{min}$ in the range over $40^{\circ} \mathrm{C}$, with detection at $260 \mathrm{~nm}$. The first derivative was calculated from each UV-melting profile and $T_{\mathrm{m}}$ was determined. For the trans-nucleotide construct, the concentrations of both strands were $\sim 1 \mu \mathrm{M}$ and measurement was performed at a scan rate of $0.5^{\circ} \mathrm{C} / \mathrm{min}$ across the whole temperature range. 
Hamachi et al.

\section{Results}

3.1. Glycine-independent function of glycine riboswitch in the presence of PEG or ethylene glycol

Glycine-dependent expression of downstream genes has been reported both in vitro and in vivo (Mandal et al., 2004). We analyzed the level of RNA transcription mediated by T7 RNA polymerase in vitro. The eGFP construct was made for future in vivo analysis. Consistent with the previous results, the level of full-length transcribed RNA ( ca. $1100 \mathrm{nt}$ ) was increased by the addition of glycine (Fig. 2A). However, interestingly, in the presence of PEG, transcription of full-length RNA was inhibited and was not dependent on glycine (Fig. 2B). The length of the major product corresponded to that of the glycine riboswitch ( ca. 270 nt) (Fig. 2B). Glycine-independent gene expression was also observed upon addition of ethylene glycol, but the quantity of fulllength RNA was higher than that of the RNA with the length corresponding to the glycine riboswitch (Fig. 2C). These results suggest that subtle conformational changes induced by PEG or ethylene glycol can inhibit glycine-dependent transcriptional regulation.

\subsection{Importance of the terminator stem in transcription}

Glycine-independent transcription of RNA by PEG or ethylene glycol suggests that the putative intrinsic terminator stem formation is a key determinant of the phenomenon. The last part of aptamer II of the B. subtilis glycine riboswitch contains sequences that are complementary to a part of the expression platform (Fig. 1). To investigate this experimentally, we constructed transcription systems in which aptamers I 
Hamachi et al.

and II were deleted (Fig. 1). In contrast to the system with these aptamers, glycine dependence was not detected irrespective of the presence of PEG or ethylene glycol (Fig. $3 \mathrm{~A}-\mathrm{C})$. In this truncated system, the effect of PEG or ethylene glycol on transcription had a similar trend to that of the complete system with aptamers I and II; PEG inhibited and ethylene glycol enhanced transcription. Furthermore, the pET23a plasmid coding eGFP alone (without aptamers I and II and the terminator stem) was used for transcription, and irrespective of the presence of glycine, PEG and ethylene glycol, only full-length products were detected (Fig. 3D-F).

The terminator stem is composed of a stem1-bulge-stem2-loop structure. Fig. 4 shows the amount of transcription obtained with various templates that harbor mutations around the putative terminator stem region in the presence of $10 \%$ PEG. Templates without glycine aptamers were used in lanes 1 and 2, and templates with tandem glycine aptamers were used in lanes 3-5 (Fig. 4). Terminated transcriptional product was detected only when the terminator stem and the poly-U stretch were intact, irrespective of the presence of glycine aptamers (Fig. 4, lane 1, arrow (a)). Transcriptions from both a template with non-complementary sequences at the position corresponding to stem 1 region and a template with a partially deleted stem 1 region produced full-length RNA (Fig. 4, lanes 2-4, arrow (b)). These results underline the importance of terminator stem formation. Similarly, full-length RNA was also produced from a template harboring a deletion of poly-U after the putative terminator stem (Fig. 4, lane 5, arrow (b)). This finding is consistent with the previous results that showed that the terminator hairpin, including the poly- $U$ stretch, is necessary for the termination in the context of T7 RNA polymerase (Macdonald et al., 1993). 
Hamachi et al.

\subsection{Structure of the terminator stem}

We focused on the terminator stem itself and performed a native gel electrophoretic characterization of the stem and its derivatives. The RNA sequences used in this electrophoresis are shown in Fig. 5. They are based on the last 11 nucleotides of aptamer II of the B. subtilis glycine riboswitch and the downstream sequences of the expression platform, forming a putative stem-bulge-stem loop structure. As shown in Fig. 5 , the dimer control construct showed mobility similar to that of tRNA ${ }^{\text {Ala }}$. However, the wild-type terminator stem and the bulgeless constructs moved almost as the same as the minihelix. These results indicate that the wild-type and bulgeless terminator stems behaved as monomers.

\subsection{FRET and UV-monitored thermal denaturation analysis of the conformation of the} PEG- or ethylene glycol-dependent terminator stem

To investigate the effect of addition of PEG or ethylene glycol on terminator stem stability, we performed FRET analysis (Mergny, 1999; Mergny and Maurizot, 2001; Umehara et al., 2012). The RNA used in this analysis was the wild-type terminator stem, which is composed of a stem-bulge-stem-loop structure, and the sequence was the same as shown in Fig. 5. The RNA was labeled with 5'-fluorescein and 3'-DABCYL. FRETmediated quenching between the fluorophore and the quencher was observed in the presence of PEG, whereas fluorescence emission spectra were observed in absence of PEG (Fig. 6). In contrast, fluorescence emission was increased upon addition of ethylene glycol (Fig. 6). 
Hamachi et al.

Fig. 7A shows the UV-melting curves for the wild-type terminator stem in the absence and presence of PEG or ethylene glycol. The average melting temperature $\left(T_{\mathrm{m}}\right)$ increased from $52.5^{\circ} \mathrm{C}$ to $54.5^{\circ} \mathrm{C}$ in the presence of $10 \% \mathrm{PEG}$ and to $57.4^{\circ} \mathrm{C}$ in the presence of $20 \%$ PEG. On the other hand, $T_{\mathrm{m}}$ was decreased to $51.5^{\circ} \mathrm{C}$ in the presence of $10 \%$ ethylene glycol, and to $48.5^{\circ} \mathrm{C}$ in the presence of $20 \%$ ethylene glycol (Fig. 7A). In the case of the bulgeless terminator stem (Fig. 7B), the average $T_{\mathrm{m}}$ in the absence of PEG is $61.5^{\circ} \mathrm{C}$ and the value also increased to $63.5^{\circ} \mathrm{C}$ with $10 \%$ PEG and to $64.4^{\circ} \mathrm{C}$ with $20 \%$ PEG. The $T_{\mathrm{m}}$ decreased to $58.5^{\circ} \mathrm{C}$ and $56.3^{\circ} \mathrm{C}$ in the presence of $10 \%$ and $20 \%$ ethylene glycol, respectively (Fig. 7B). The presence of $1 \mathrm{mM}$ glycine, a concentration that affects glycine riboswitch activity, did not change the $T_{\mathrm{m}}$ of the wild-type terminator stem (Fig. 8A) or the bulgeless terminator stem (Fig. 8B).

\subsection{Role of the loop in the terminator stem}

The terminator stem is composed of a hairpin-like cis-construct. In order to evaluate the contribution of the loop, we also measured the $T_{\mathrm{m}}$ of the two complementary 17-mer RNAs (trans-construct), which corresponds to the stem region of the bulgeless terminator. The $T_{\mathrm{m}}$ was $54.4^{\circ} \mathrm{C}$ (Fig. $8 \mathrm{C}-\mathrm{D}$ ), which is $7.1^{\circ} \mathrm{C}$ lower than that of the cisconstruct (stem-loop) (Fig. 7B). Therefore, loop function is important for the formation

of a stable complementary helix. The influence of PEG and ethylene glycol on the stability of the structure in the trans-construct showed a similar trend to that of the cisconstruct (Fig. 8C-D). Interestingly, the $T_{\mathrm{m}}$ of the two complementary 17-mer DNAs (that differed only at one base, which was either $\mathrm{U}$ [RNA] or T [DNA]) was $35.8^{\circ} \mathrm{C}$ (Fig. 
Hamachi et al.

$8 \mathrm{E}-\mathrm{F})$. This is approximately $20^{\circ} \mathrm{C}$ lower than that of the two complementary RNA constructs (Fig. 8C-D).

Page 13 of 25 
Hamachi et al.

\section{Discussion}

The X-ray structure of the $F$. nucleatum glycine riboswitch indicated that each aptamer is composed of three helical structures (a P1 helix branching away from the P2P3 helices). The aptamers dimerize by packing the P1 helix of one aptamer against the P3 helix and that A-minor interactions between $\mathrm{P} 1$ and $\mathrm{P} 3$ are responsible for cooperative glycine binding (Butler et al., 2011; Huang et al., 2010). The glycine binding site is composed around a universally conserved U, which presents its Watson-Crick face to hydrogen bond with glycine. Conversely, the opposite $\mathrm{A}$ is flipped out to create a cavity for glycine binding, and the entrance to the glycine binding site is framed by several phosphate backbones stabilized by a pair of metals (Butler et al., 2011). Despite such structural approaches, the regulatory mechanism of glycine-dependent gene expression is not clear. This is partly because the structures solved so far are those containing only two tandem aptamers or a single aptamer of the riboswitch (without the expression platform) (Butler et al., 2011; Huang et al., 2010). However, judging from the behavior of the terminator stem in the present study, the key for the molecular ON/OFF switch lies in the portion including the terminator stem.

Glycine riboswitches may not display cooperative binding under physiological conditions (Baird and Ferré-D’Amaré, 2013; Sherman et al., 2012), but our results using T7 RNA polymerase indicate that the basic structure of the B. subtilis glycine riboswitch contains properties imparting the capability to function in "glycine-dependent" gene expression. T7 RNA polymerase has also been shown to work in several Sadenosylmethionine riboswitches (Winkler et al., 2003). Notably, the riboswitch behaves in a "glycine-independent" manner in the presence of PEG and ethylene glycol, which 
Hamachi et al.

have opposite effects on transcription as well as on stable terminator stem formation. Regardless of the presence of aptamer I and II regions in the template, full-length transcriptional products were similarly formed by adding ethylene glycol. These results clearly show that ethylene glycol does not work as a ligand instead of glycine, despite the structural similarities of these molecules.

The $T_{\mathrm{m}}$ of the wild-type terminator stem (and that of the bulgeless terminator stem) decreased in the presence of ethylene glycol, whereas addition of PEG increased the $T_{\mathrm{m}}$. An intracellular environment in which the total concentration of biomolecules reaches $400 \mathrm{~g} \mathrm{~L}^{-1}$ creates a situation referred to as molecular crowding (Miyoshi and Sugimoto, 2008). To mimic molecular crowding in vitro, PEG-like molecules (PEG, ethylene glycol, or glycerol) are utilized as crowding co-solutes. The excluded-volume effect of these additives is thought to be due to the changes in the $T_{\mathrm{m}}$ of the nucleic acids (Minton, 1998). Long DNA duplexes are destabilized by small co-solutes, whereas the duplexes are stabilized by large co-solutes (Nakano et al., 2004; Spink and Chaires, 1999). Although the terminator stem of the glycine riboswitch is composed of only 17 complementary base pairs (with bulge), we infer from the $T_{\mathrm{m}}$ values that the structure (with or without the bulge) is destabilized by ethylene glycol, but stabilized by PEG.

The behavior of the $T_{\mathrm{m}}$ of DNA and RNA duplexes was quite different. The 17mer complementary RNA duplex had a $T_{\mathrm{m}}$ about $20^{\circ} \mathrm{C}$ higher than that of the DNA duplex. This result is probably due to the differences of stacking effects between DNA (B-form) and RNA (A-form). The stability was greatly increased by connecting the two strands through a loop, which consists of a hairpin structure. 
Hamachi et al.

A hairpin structure is typically seen in the minihelix domain of tRNA. Evolutionarily, the development of tRNA would have begun with a minihelix to which an anticodon containing another hairpin domain was added later (Di Giulio, 1992; Rodin et al., 1996; Schimmel and Ribas de Pouplana, 1995; Tamura, 2008, 2011; Tamura and Schimmel, 2004, 2006). Correspondingly, the conserved active site domain of aminoacyl tRNA synthetases incorporates sequences for minihelix recognition, whereas the nonconserved domain interacts with more distal parts of the tRNA structure, including anticodons (Schimmel et al., 1993). This fact suggests that the anticodon recognition domain of aminoacyl tRNA synthetases occurred after the establishment of the active site domain.

Analogous to these observations, ligand-binding aptamer domains of riboswitches likely evolved after the emergence of an expression platform consisting only of a simple stem and loop structure, because varieties of ligands and common gene-regulating function are seen in riboswitches. Hairpin RNA, together with the involvement of the bulge, could have been affected dynamically by PEG-like molecules. Ethylene glycol is one of the most abundant polyols found in meteorites (Cooper et al., 2001). Apart from the origin of ethylene glycol, such organic compounds may have played an important role in the formation of RNA building blocks in the initial stage of evolution. In particular, some conditions may have produced primitive riboswitches owing to changes in glycol concentrations. In the scheme of molecular evolution, transition from a glycineindependent riboswitch to a glycine-dependent riboswitch could have occurred with the addition of the aptamer domain for glycine. Glycine is thought to have been abundant on 
Hamachi et al.

primitive Earth, and the initial evolution of riboswitches might have begun using glycine as a ligand.

PEG is often used to simulate the crowded environment of the cell, but the cellular environment is not necessarily similar to a situation with solely high concentrations of PEG present. Defining the relationship between our experimental results and the role of PEG in the cell is difficult because it requires knowledge of the true process of the origination and evolution of cells. We should not comment on it, but we can emphasize that PEG and ethylene glycol affect the formation of the terminator stem and that the RNA component intrinsically behaves in a glycine-independent manner in the presence of such organic compounds. 
Hamachi et al.

\section{Acknowledgments}

We thank Professor Gota Kawai (Chiba Institute of Technology) for the helpful discussions, Professor Shigetoshi Miura (Tokyo University of Science) and Dr. Subray S. Hegde (Albert Einstein College of Medicine) for kindly providing plasmids, Professor Koichi Ito (University of Tokyo) for kindly providing B. subtilis genomic DNA. This work was supported by a grant from PRESTO (RNA and Biofunctions), the Japan Science and Technology Agency (JST), Japan, Grants-in Aid for Scientific Research from the Ministry of Education, Science, Sports and Culture, Japan (Grant No. 23657160 to K.T. and 24710231 to T.U.), and the program for the development of strategic research center in private universities by MEXT, Japan. 
Hamachi et al.

\section{References}

Baird, N.J., Ferré-D’Amaré, A.R. 2013. Modulation of quaternary structure and enhancement of ligand binding by the K-turn of tandem glycine riboswitches RNA $19,167-176$.

Butler, E.B., Xiong, Y., Wang, J., Strobel, S.A. 2011. Structural basis of cooperative ligand binding by the glycine riboswitch. Chem. Biol. 18, 293-298.

Cooper, G., Kimmich, N., Belisle, W., Sarinana, J., Brabham, K., Garrel, L. 2001. Carbonaceous meteorites as a source of sugar-related organic compounds for the early Earth. Nature 414, 879-883.

Di Giulio, M. 1992. On the origin of the transfer RNA molecule. J. Theor. Biol. 159, $199-214$.

Erion, T.V., Strobel, S.A. 2011. Identification of a tertiary interaction important for cooperative ligand binding by the glycine riboswitch. RNA 17, 74-84.

Francklyn, C., Schimmel, P. 1989. RNA minihelices can be aminoacylated with alanine. Nature 337, 478-481.

Huang, L., Serganov, A., Patel, D.J. 2010. Structural insights into ligand recognition by a sensing domain of the cooperative glycine riboswitch. Mol. Cell 40, 774-786.

Kwon, M., Strobel, S.A. 2008. Chemical basis of glycine riboswitch cooperativity. RNA $14,25-34$.

Lipfert, J., Das, R., Chu, V.B., Kudaravalli, M., Boyd, N., Herschlag, D., Doniach, S. 2007. Structural transitions and thermodynamics of a glycine-dependent riboswitch from Vibrio cholerae. J. Mol. Biol. 365, 1393-1406. 


\section{Hamachi et al.}

Macdonald, L.E., Zhou, Y., McAllister, W.T. 1993. Termination and slippage by bacteriophage T7 RNA polymerase. J. Mol. Biol. 232, 1030-1047.

Mandal, M., Lee, M., Barrick, J.E., Weinberg, Z., Emilsson, G.M., Ruzzo, W.L., Breaker, R.R. 2004. A glycine-dependent riboswitch that uses cooperative binding to control gene expression. Science 306, 275-279.

Mergny, J.L. 1999. Fluorescence energy transfer as a probe for tetraplex formation: the imotif. Biochemistry 38, 1573-1581.

Mergny, J.L., Maurizot, J.C. 2001. Fluorescence resonance energy transfer as a probe for G-quartet formation by a telomeric repeat. Chembiochem 2, 124-132.

Miller, S.L. 1953. A production of amino acids under possible primitive earth conditions. Science $117,528-529$.

Minton, A.P. 1998. Molecular crowding: analysis of effects of high concentrations of inert cosolutes on biochemical equilibria and rates in terms of volume exclusion. Methods Enzymol. 295, 127-149.

Miyoshi, D., Sugimoto, N. 2008. Molecular crowding effects on structure and stability of DNA. Biochimie 90, 1040-1051.

Nakano, S., Karimata, H., Ohmichi, T., Kawakami, J., Sugimoto, N. 2004. The effect of molecular crowding with nucleotide length and cosolute structure on DNA duplex stability. J. Am. Chem. Soc. 126, 14330-14331.

Nudler, E., Mironov, A.S. 2004. The riboswitch control of bacterial metabolism. Trends Biochem. Sci. 29, 11-17.

Rodin, S., Rodin, A., Ohno, S. 1996. The presence of codon-anticodon pairs in the acceptor stem of tRNAs. Proc. Natl. Acad. Sci. USA 93, 4537-4542. 
Hamachi et al.

Roth, A., Breaker, R.R. 2009. The structural and functional diversity of metabolitebinding riboswitches. Annu. Rev. Biochem. 78, 305-334.

Schimmel, P., Giegé, R., Moras, D., Yokoyama, S. 1993. An operational RNA code for amino acids and possible relationship to genetic code. Proc. Natl. Acad. Sci. USA $90,8763-8768$.

Schimmel, P., Ribas de Pouplana, L. 1995. Transfer RNA: from minihelix to genetic code. Cell 81, 983-986.

Sherman, E.M., Esquiaqui, J., Elsayed, G., Ye, J.D. 2012. An energetically beneficial leader-linker interaction abolishes ligand-binding cooperativity in glycine riboswitches. RNA 18, 496-507.

Spink, C.H., Chaires, J.B. 1999. Effects of hydration, ion release, and excluded volume on the melting of triplex and duplex DNA. Biochemistry 38, 496-508.

Takahashi, K.I., Baba, S., Chattopadhyay, P., Koyanagi, Y., Yamamoto, N., Takaku, H., Kawai, G. 2000. Structural requirement for the two-step dimerization of human immunodeficiency virus type 1 genome. RNA 6, 96-102.

Tamura, K. 2008. Origin of amino acid homochirality: relationship with the RNA world and origin of tRNA aminoacylation. BioSystems 92, 91-98.

Tamura, K. 2011. Molecular basis for chiral selection in RNA aminoacylation. Int. J. Mol. Sci. 12, 4745-4757.

Tamura, K., Schimmel, P. 2004. Chiral-selective aminoacylation of an RNA minihelix. Science 305, 1253. 
Hamachi et al.

Tamura, K., Schimmel, P.R. 2006. Chiral-selective aminoacylation of an RNA minihelix: mechanistic features and chiral suppression. Proc. Natl. Acad. Sci. USA 103, $13750-13752$.

Umehara, T., Kitagawa, T., Nakazawa, Y., Yoshino, H., Nemoto, R., Tamura, K. 2012. RNA tetraplex as a primordial peptide synthesis scaffold. BioSystems 109, 145150.

Winkler, W.C., Breaker, R.R. 2005. Regulation of bacterial gene expression by riboswitches. Annu. Rev. Microbiol. 59, 487-517.

Winkler, W.C., Nahvi, A., Sudarsan, N., Barrick, J.E., Breaker, R.R. 2003. An mRNA structure that controls gene expression by binding S-adenosylmethionine. Nat. Struct. Biol. 10, 701-707.

Yarnell, W.S., Roberts, J.W. 1999. Mechanism of intrinsic transcription termination and antitermination. Science 284, 611-615. 
Hamachi et al.

\section{Figure legends}

Fig. 1. (A) Schematic representation of the secondary structure of the B. subtilis glycine riboswitch composed of tandem aptamers and expression platform. The nucleotides in the putative intrinsic terminator stem are explicitly indicated. Shading shows complementary sequences. Arrows indicate the positions for preparing the aptamerdeleted (I and II) mutant. (B) Schematic representation of the plasmid construct. The glycine riboswitch region was ligated into $X b a \mathrm{I}$ site of eGFP vector (pET23a). (C) The sequence of the B. subtilis glycine riboswitch and the eGFP gene. The original plasmid for eGFP expression was prepared between the NdeI and XhoI sites. A region of the glycine riboswitch (shown in italics) was ligated into the $\mathrm{XbaI}$ site of the eGFP vector (pET23a). The translated sequence and corresponding amino acids are shown. Underlined areas indicate the regions corresponding to aptamers I and II, which were deleted for further experiments.

Fig. 2. In vitro transcription by T7 RNA polymerase by using the template DNA that consists of the $\mathrm{T} 7$ promoter, the B. subtilis glycine riboswitch (aptamers I and II and terminator stem), and the eGFP gene in the presence of glycine at varying concentrations (A). The results in the presence of $10 \%$ PEG (B) or $10 \%$ ethylene glycol (C) are also shown. Reaction time was 30 min.

Fig. 3. In vitro transcription by $\mathrm{T} 7 \mathrm{RNA}$ polymerase by using the template DNA that consists the $\mathrm{T} 7$ promoter, terminator stem, and eGFP gene in the presence of glycine at varying concentrations (A). The results in the presence of $10 \%$ PEG (B) or $10 \%$ ethylene 
Hamachi et al.

glycol (C) are also shown. As control, the results using the template DNA that consists of the T7 promoter and the eGFP gene are written together: (D) absence of PEG and ethylene glycol, (E) 10\% PEG, (F) 10\% ethylene glycol. Reaction time was 30 min.

Fig. 4. In vitro transcription by $\mathrm{T} 7 \mathrm{RNA}$ polymerase using various templates around the terminator stem of the expression platform of the B. subtilis glycine riboswitch in the presence of $10 \%$ PEG. Templates without glycine aptamers were used in lanes 1 and 2, and templates with tandem glycine aptamers were used in lanes 3-5. Reaction time was 330 min.

Fig. 5. Electrophoretic mobility shift assay of the wild-type terminator stem (43 nt) and bulgeless terminator stem (39 nt), together with the dimer control, tRNA ${ }^{\text {Ala }}$ transcript (76 nt) and minihelix ${ }^{\text {Ala }}(35 \mathrm{nt})$. The nucleotides were separated via $10 \%$ native PAGE. The gel was stained with $0.04 \%$ toluidine blue.

Fig. 6. FRET analysis for the putative terminator stem in the presence of PEG or ethylene glycol. Fluorescein and DABCYL were attached at the 5'-end and 3'-end, respectively. The quenching effect was observed by $490 \mathrm{~nm}$ excitation.

Fig. 7. UV-monitored thermal denaturation analysis for the wild-type terminator stem (A) and the bulgeless terminator stem (B) in the presence of PEG or ethylene glycol. Melting was assessed by determining the UV absorbance at $260 \mathrm{~nm}$. 
Hamachi et al.

Fig. 8. UV-monitored thermal denaturation analysis. (A) The wild-type terminator stem in the presence or absence of $1 \mathrm{mM}$ glycine. (B) A bulgeless terminator stem in the presence or absence of $1 \mathrm{mM}$ glycine. (C) Two complementary 17-mer RNAs (transconstructs) in the presence of PEG. (D) Two complementary 17-mer RNAs (transconstructs) in the presence of ethylene glycol. (E) Two complementary 17-mer DNAs (trans-constructs) in the presence of PEG. (F) Two complementary 17-mer DNAs (transconstructs) in the presence of ethylene glycol. Melting was assessed by determining the UV absorbance at $260 \mathrm{~nm}$. 


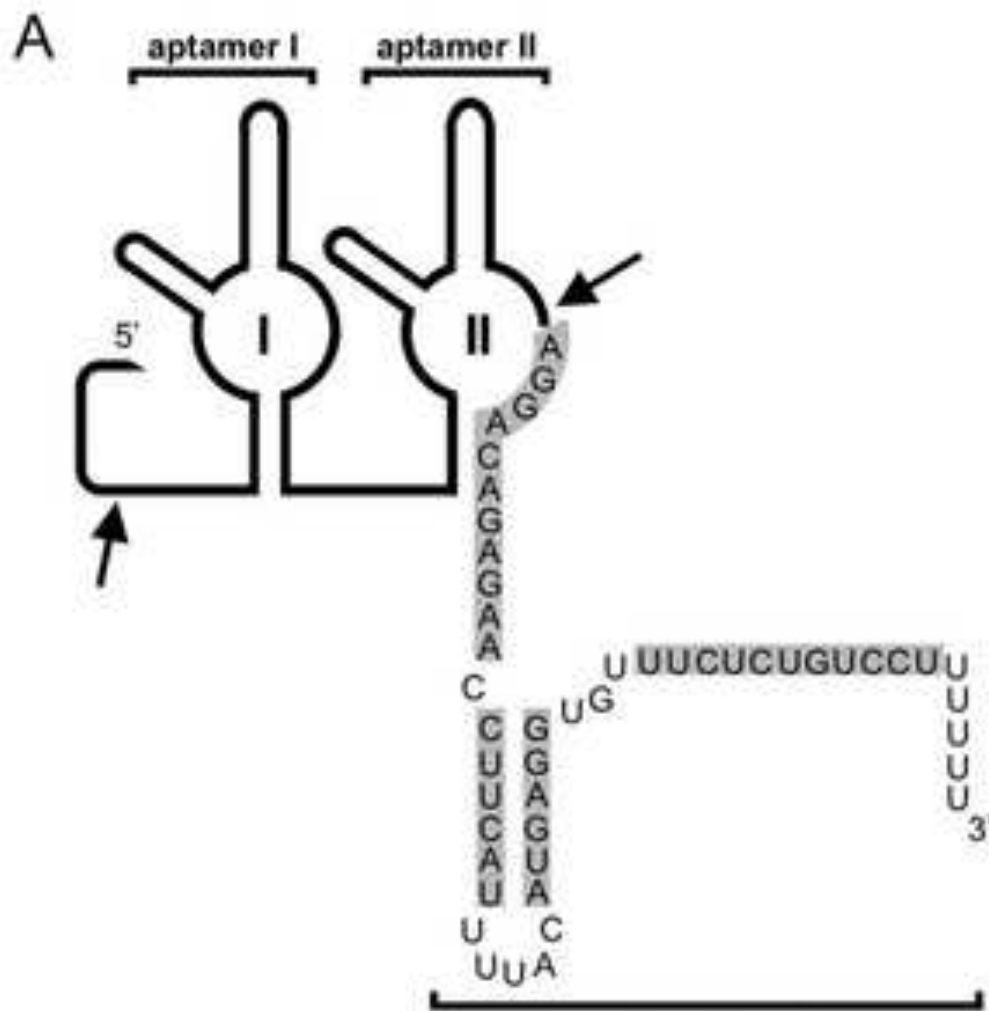

expression platform

B

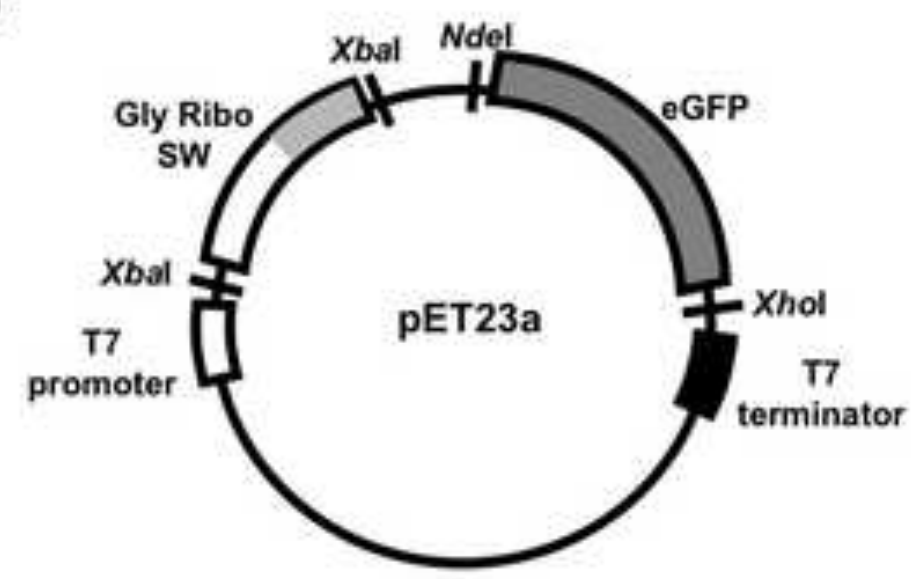

C

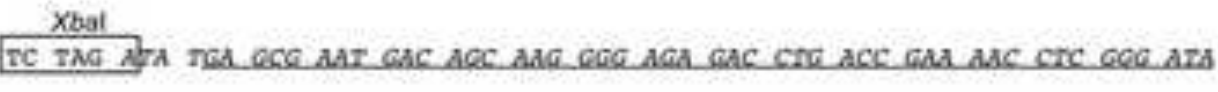

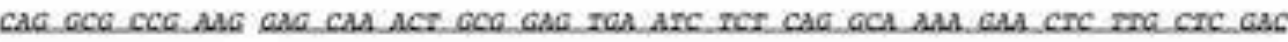

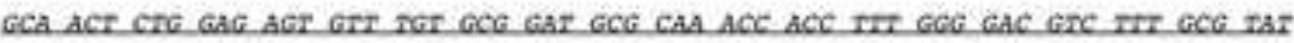
GCA AAG TAA ACT TRC ACG TGC CAG GAC AGA GAA COT TCA TIT TAC ATG AOG TOT TTE TET

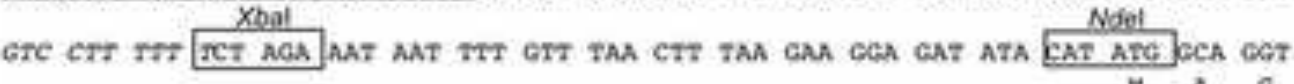

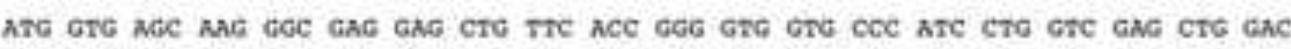

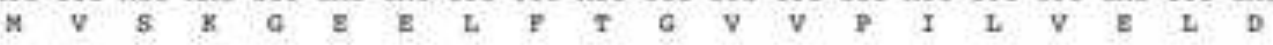

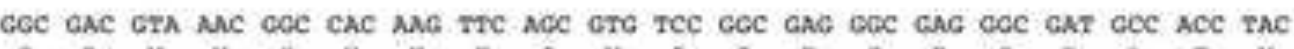

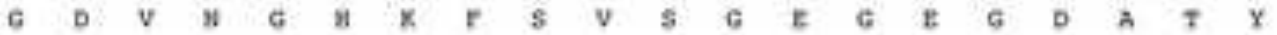
GCC AAG CTC ACC CTS AAC TTC ATC THC ACC ACC GCC AAG CTC CCC GRC CCC TOC CCC ACC

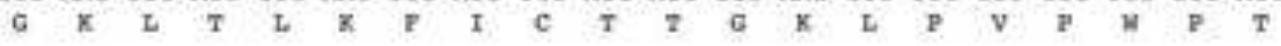
CTC GTC ACC ACC CTE ACC IAC ECC GTG CAG TGC ITC MOC OCC TAC CCC GAC CAC ATC NAC

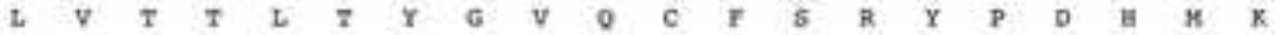
CAG CAC CAC TTC TTC ANG TCC OCC ATG CCC GAA GOC TAC GTC CAC GAG COC ACC ATC TTC

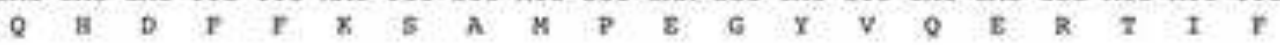
TRC AAC GAC CAC GGC AAC TAC AAG ACC CGC GCC GAC GTC AAG TTC GAG GEC GAC ACC CIC

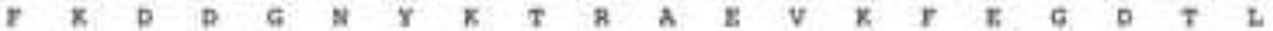

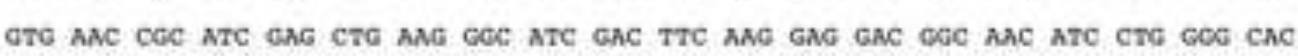

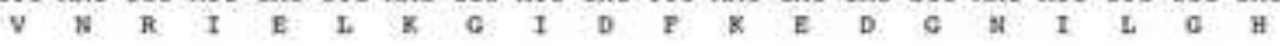

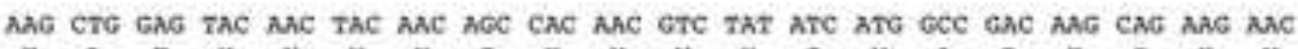

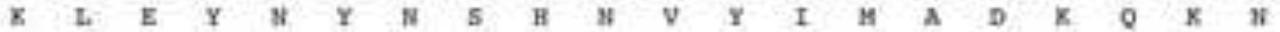

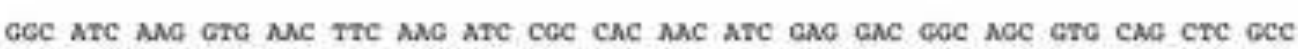

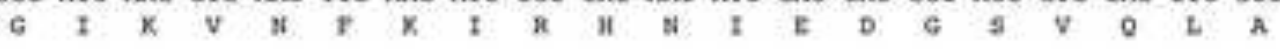
GAC CAC TAC CAG CAG AAC ACC CCC ATC GEC CAC GGC CCC GTE CTC CTG CCC GAC AAC CAC

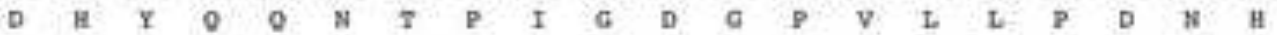
TAC CTG AGC ACC CAG TCC GCC CTE AOC NAA GAC CCC AAC GAG AAG CGC GAT CAC ATG GTC

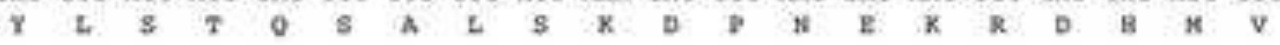

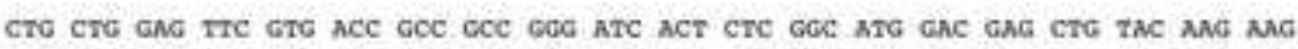

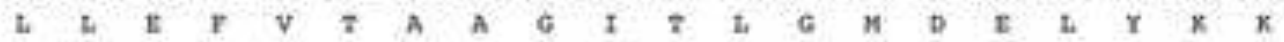

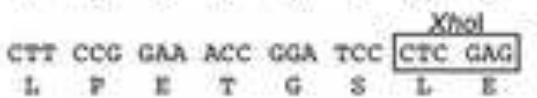




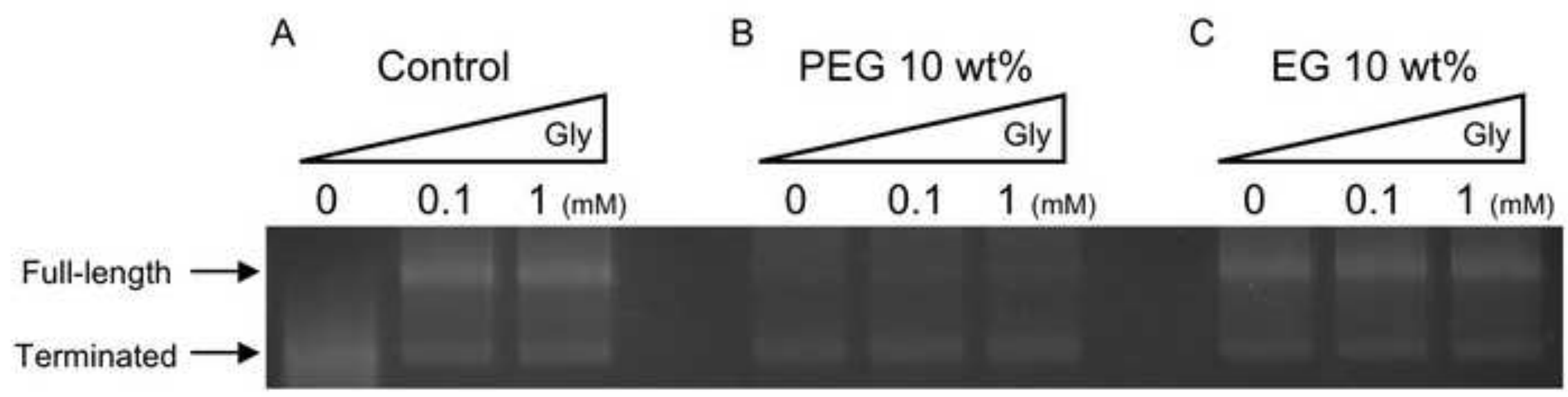


A

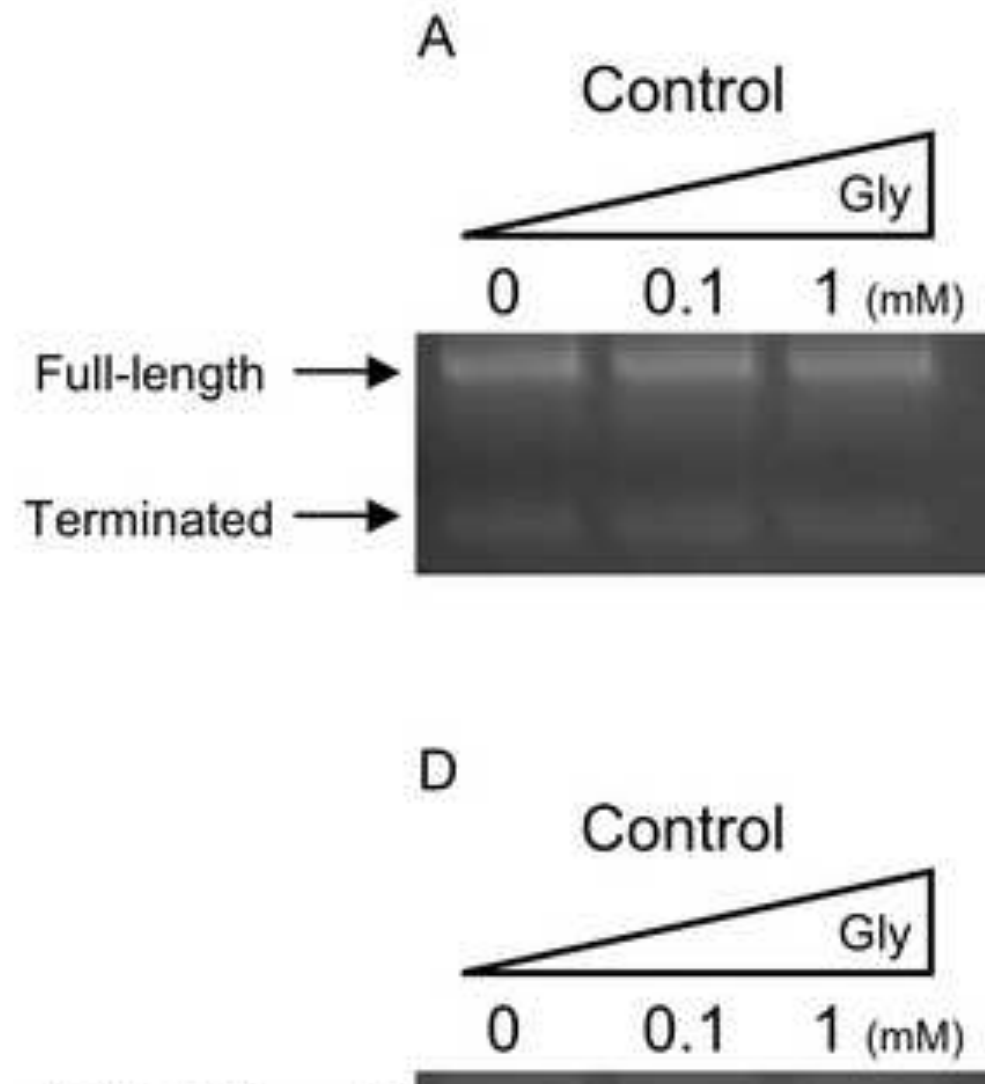

B

PEG $10 w t \%$

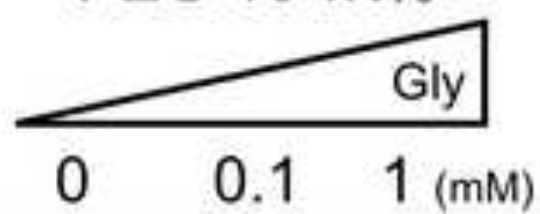

C

EG $10 w t \%$

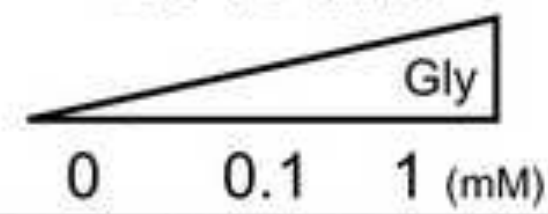

Full-length

E

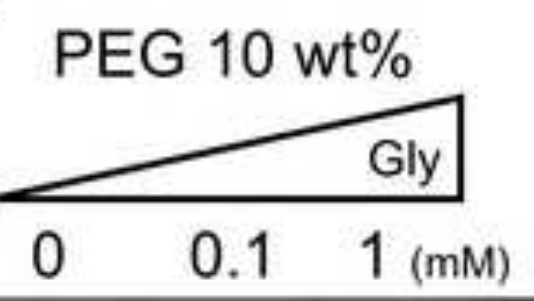

F

EG $10 w t \%$

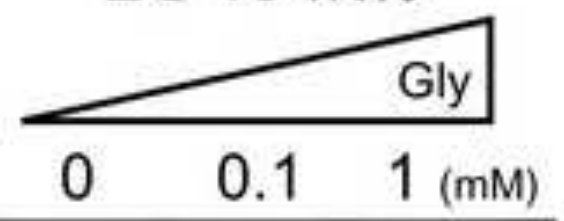




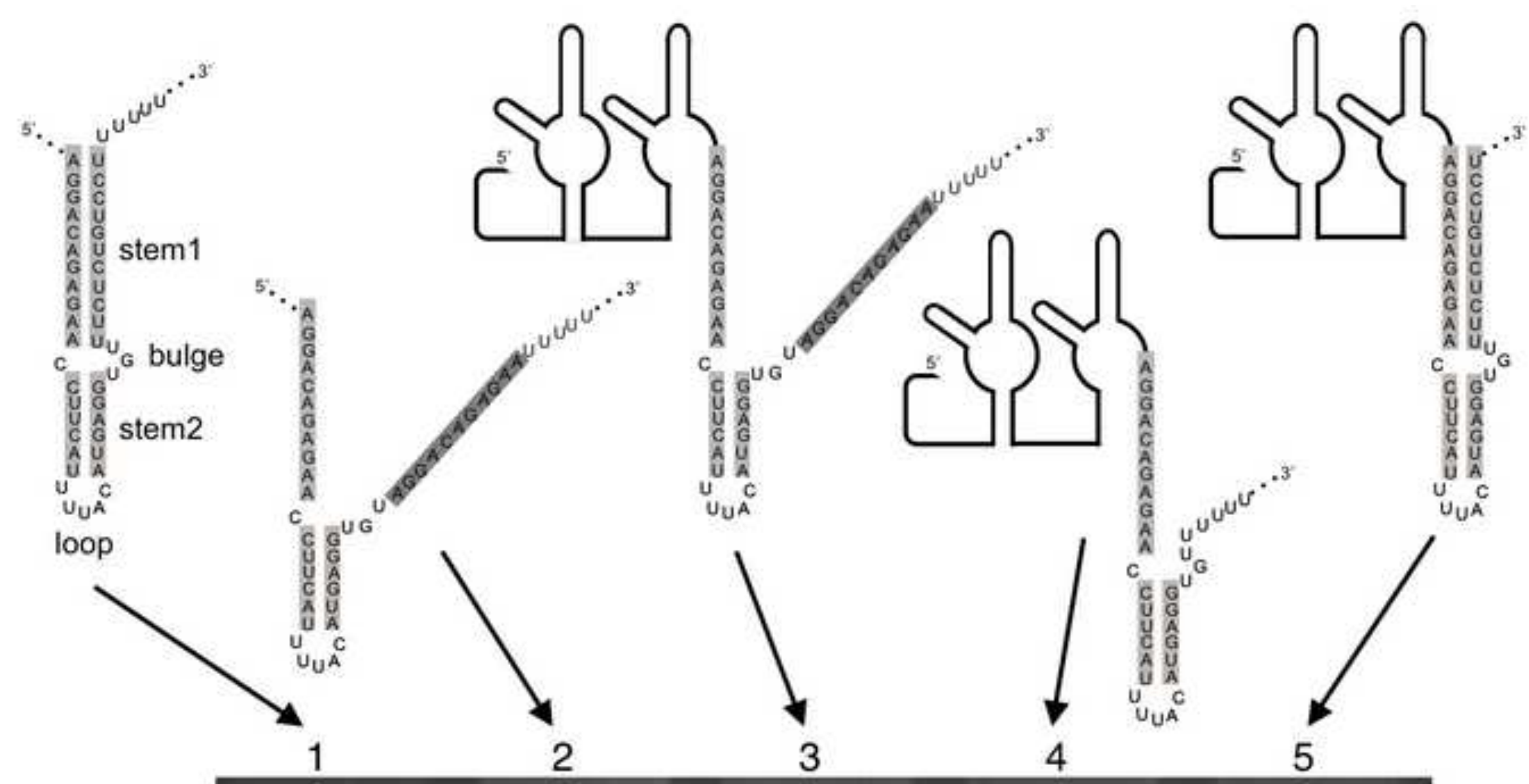

(b) $\longrightarrow$

(a) $\longrightarrow$
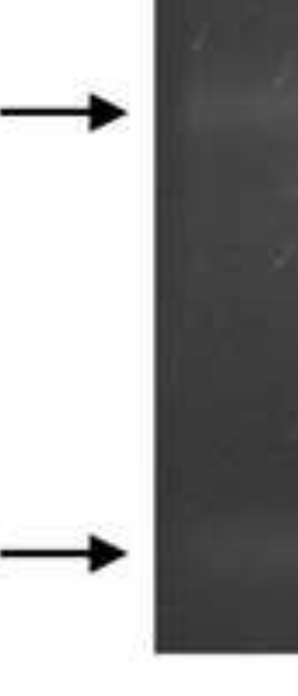


\section{Wild-type Bulgeless}

terminator terminator
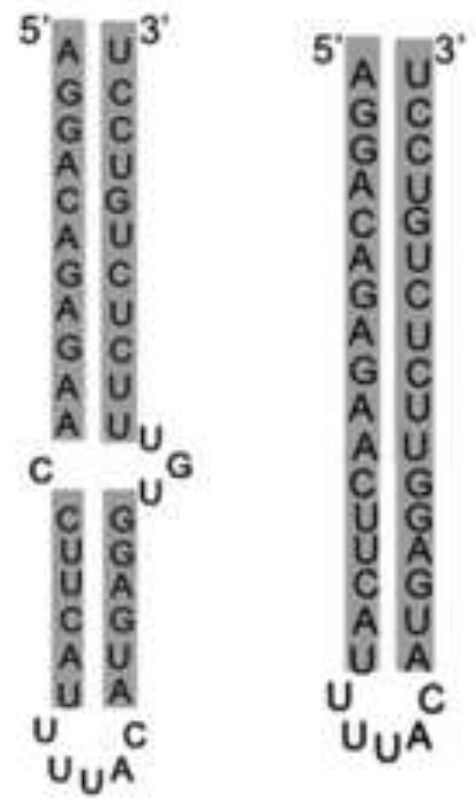


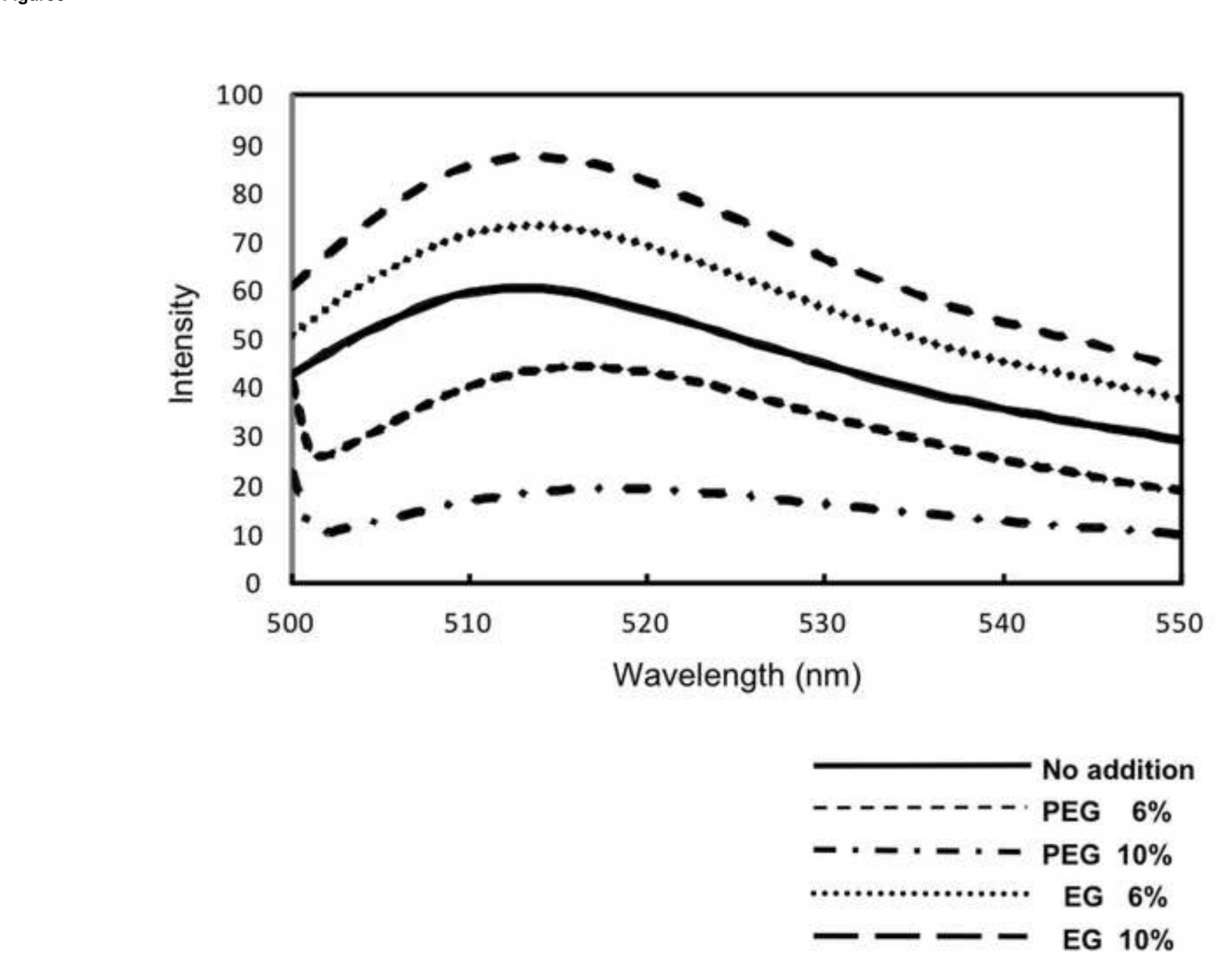

No addition

- $6 \%$

- - - PEG 10\%

..................... EG $6 \%$

-- EG $10 \%$

.



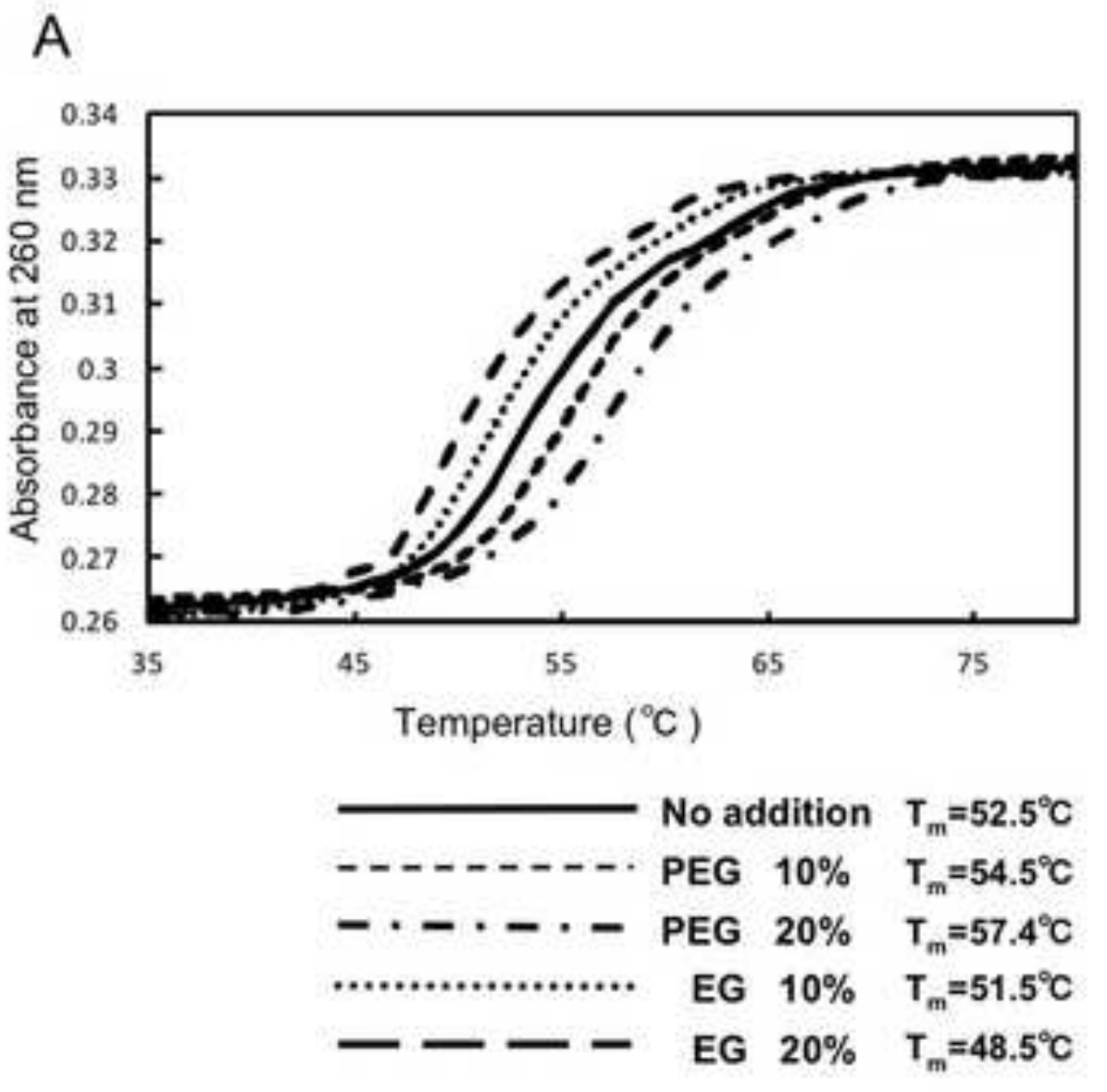
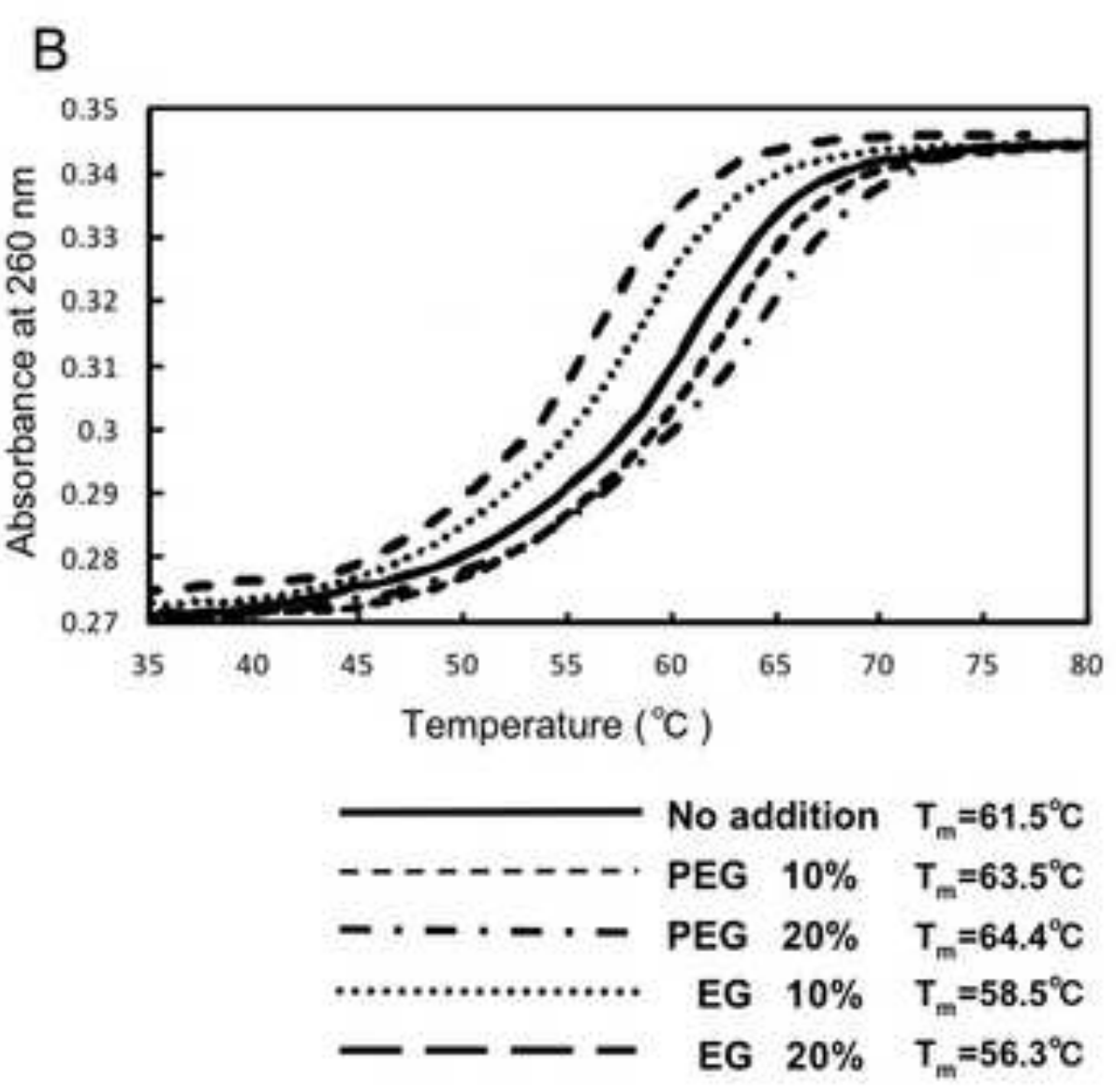
A

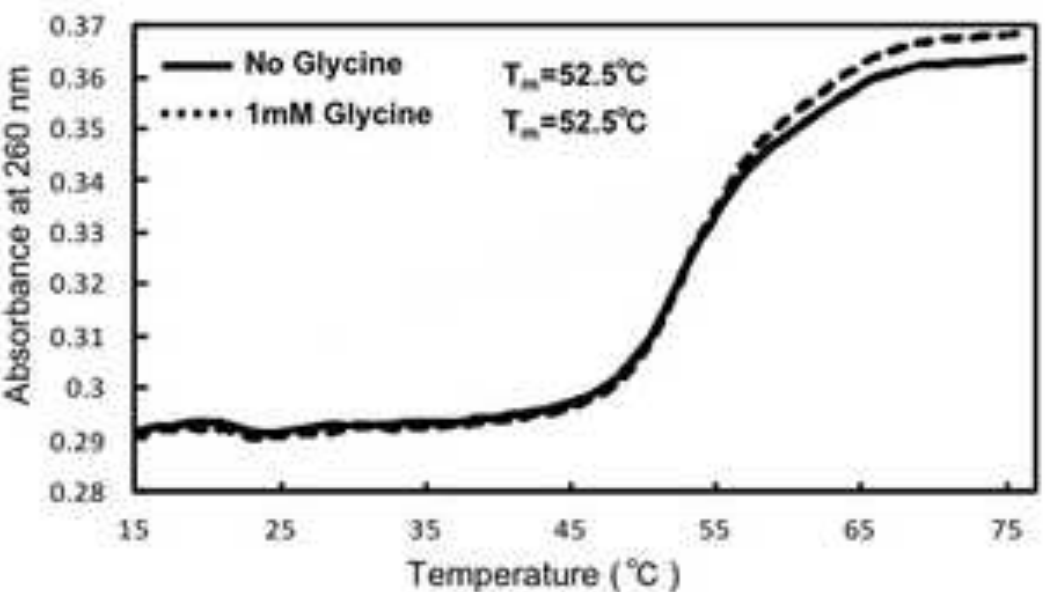

C

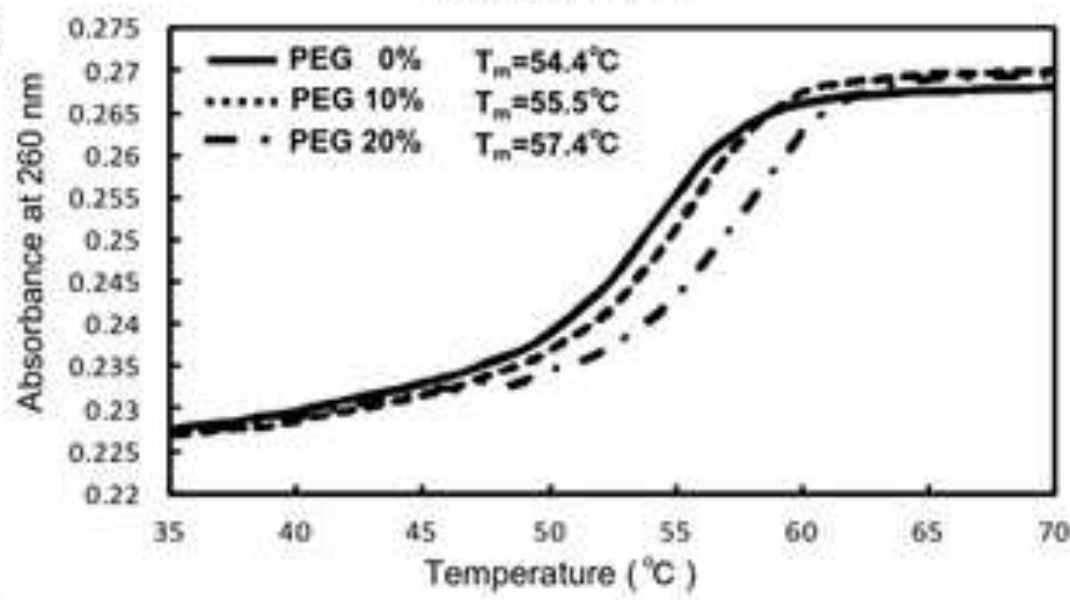

E

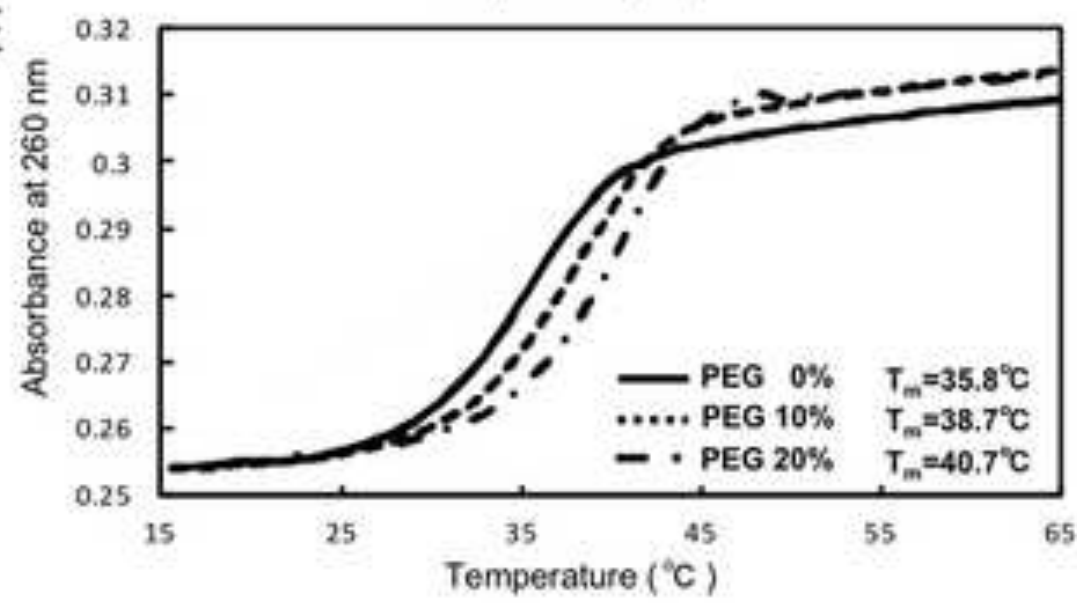

B

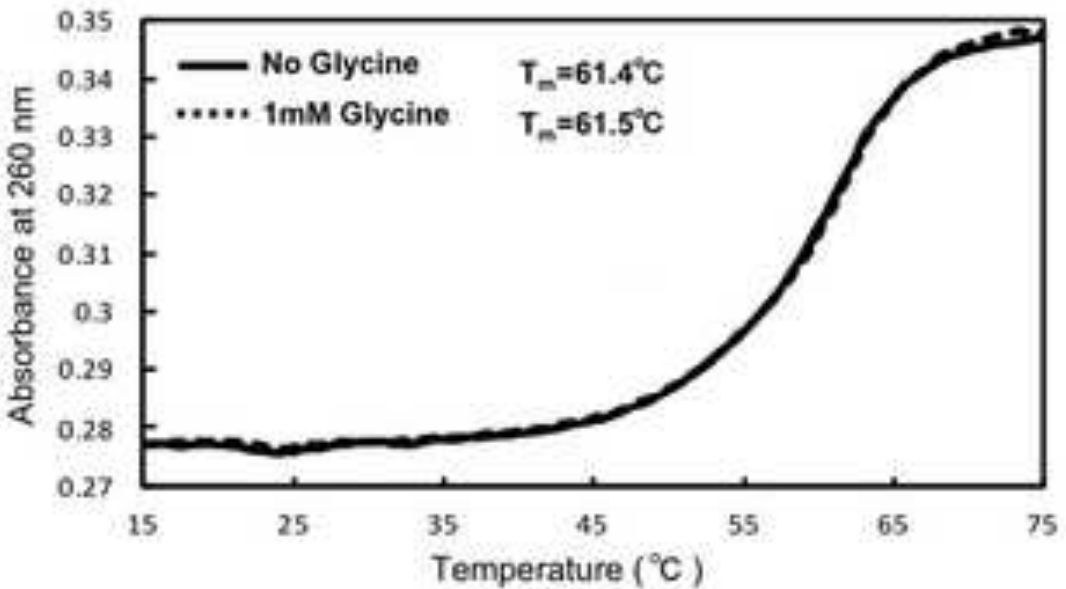

D

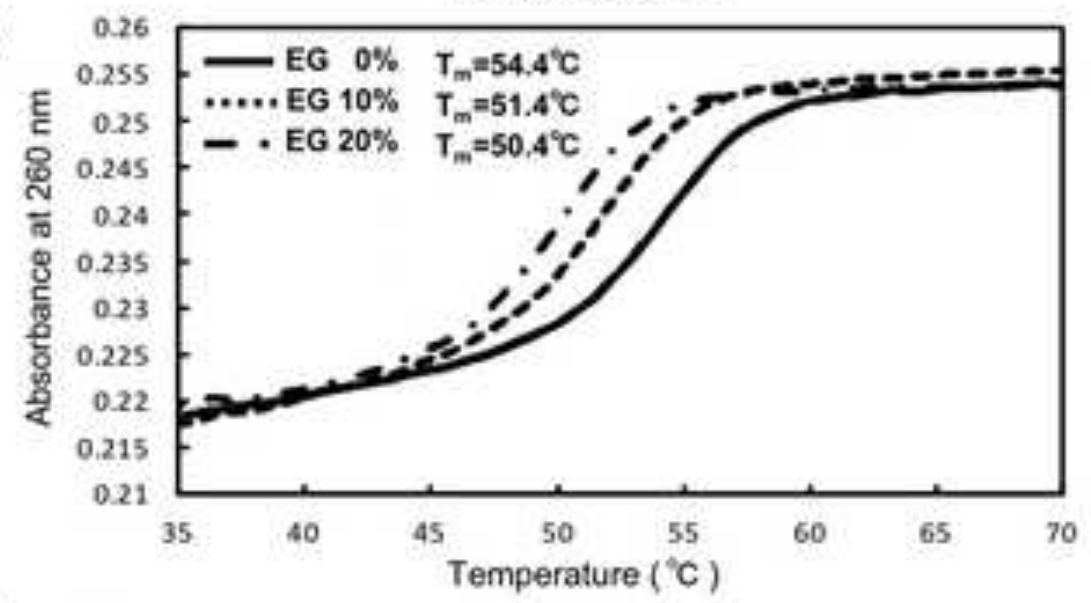

F

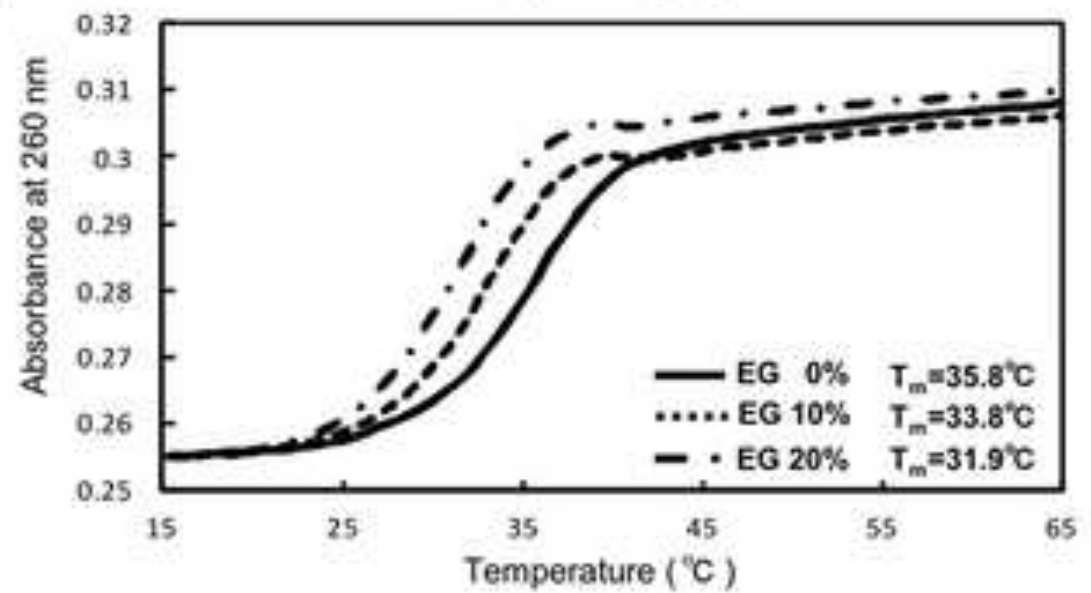

